Сейбель Н.Э.

(c) Сейбель Наталия Эдуардовна - доктор филологических наук, доцент, профессор, кафедра литературы и методики обучения литературе, Южно-уральский государственный гуманитарно-педагогический университет, 454080, Российская Федерация, г. Челябинск, пр. Ленина, 69.

E-mail: seibel_ne@mail.ru. ORCID: 0000-0002-6840-8286

\begin{abstract}
АННОТАЦИЯ
Гротеск в творчестве Петера Хакса - не просто прием, но концептуальное соединение смешного и трагического, забавного и пугающего. Произведения, жанр которых (многих из них) автор обозначил как «сказка», адресованы взрослым читателям и несут в себе палитру чувств от грустной иронии до жестокого сарказма. «Драматург двух Германий» создает образ на стыке фантастического и узнаваемого. Один из наиболее частотных способов создания гротескного образа в его произведениях - каламбур, связанный с многозначностью понятия «Величина» (Größe). Она - важная единица эстетики тонкого пародиста и автора целого корпуса гротескных пьес. Физические размеры его великанов и титанов могут совпадать или не совпадать с потенциалом личности. В первом случае персонажи попадают в поле авторского юмора, во втором - возникает гротескно-сатирический и даже гротескно-трагический эффект. Не менее важны авторские антитезы, из которых Хакс извлекает максимум смыслов. Стихия, в которой действуют его герои, создается на стыке величины и тривиальности, таланта и мещанства, духа и бытовых мелочей, силы и бессилия, уникальности и повторяемости. Автор активно использует столкновение масштабов, повторение и двойничество, столкновение телесности и сексуальности с вопросами политики, соединение человеческого и животного миров, придание сугубо абстрактным понятиям физических свойств, превращения и т. д. В совокупности череда его гротесков встраивается в авторскую концепцию исторического прогресса, базирующегося на идее объективно возникающего равновесия, вопреки часто противоположным эгоистическим стремлениям деятелей, «создающих» историю.
\end{abstract}

Ключевые слова: П. Хакс, гротеск, столкновение масштабов, повторение, телесность и сексуальность, соединение человеческого и животного, гиперлокализация, придание абстрактным понятиям физических свойств, метаморфозы.

Цитирование. Сейбель Н.Э. Гротески Петера Хакса // Вестник Самарского университета. История, педагогика, филология. 2018. Т. 24. № 2. С. 101-106. DOI: https://doi.org/10.18287/2542-0445-201824-2-101-106.

This is an open access article distributed under the Creative Commons Attribution License Which permits unrestricted use, distribution, and reproduction in any medium, provided the original work is properly cited. (CC BY 4.0) 


\title{
GROTESQUE BY PETER HACKS
}

(C) Seibel Natalia Eduardovna - Doctor of Philological Sciences, associate professor, professor, Department of Literature and Methods of Teaching Literature, South Ural State Humanitarian Pedagogical University, 69, Lenin avenue, Chelyabinsk, 454080, Russian Federation.

E-mail: seibel_ne@mail.ru. ORCID: 0000-0002-6840-8286

\begin{abstract}
A grotesque in the work of Peter Hacks is not simply reception, but conceptual connection of funny and tragic, amusing and intimidating. Genre of the works (many of them) an author designated as a «fairy-tale» are addressed to the adult readers and carry in itself the palette of feelings from sad irony to cruel sarcasm. «Dramatist of the two Germanies» creates character on a joint fantastic and knowable. One of the most frequency methods of creation of grotesque character in his works is the pun related to the polysemanticism of the concept «Size» (Größe). It is an important unit of aesthetics of thin parodist and author of whole corps of grotesque plays. The physical sizes of his giants and titans can coincide or not coincide with potential of personality. In the first case personages get in the field of authorial humour, in the second there is a grotesquely-satiric and even grotesquely-tragic effect. Authorial antitheses from that Hacks extracts a maximum of senses are no less important. An element his heroes operate in that is created on the joint of size and banality, talent and low middle class, spirit and domestic little things, force and weakness, uniqueness and repetition. An author actively uses the collision of scales, reiteration and duplicity, collision of corporality and sex appeal with the questions of politics, connection human and animal the worlds, giving the especially abstract concepts of physical properties, transformation etc. In agregate the train of his grotesques is built in authorial conception of historical progress being based on the idea of objectively nascent equilibrium, contrary often to opposite egoistical aspirations of figures, «creating» history.
\end{abstract}

Key words: P. Hacks, grotesque, collision of scales, repetition, corporeality and sexuality, combination of human and animal, hyperlocalization, giving abstract concepts of physical properties, metamorphosis.

Цитирование. Seibel N.E. Groteski Petera Khaksa [Grotesque by Peter Hacks]. Vestnik Samarskogo universiteta. Istoriia, pedagogika, filologiia [Vestnik of Samara University. History, pedagogics, philology], 2018, Vol. 24, no. 2, pp. 101-106. DOI: https://doi.org/10.18287/2542-0445-2018-24-2-101-106.

\section{Введение}

«На протяжении всего XX века в литературе происходило радикальное расширение области комического (а тем самым - и семантики самого понятия смеха), и это все заметнее сказывалось на внутренней жизни жанров, на их соотнесенности в границах различных художественных систем, на характере эстетического мышления» [Зверев, с. 378]. К творчеству Петера Хакса (1928-2003) этот вывод А.М. Зверева относится в полной мере. В текстах немецкого драматурга гармонично соединяются различные жанровые начала, преодолеваются границы исторического и сказово-мифического, комического и трагического. Отражение «противоречий без истерики» (Хакс, 2006, с. 37) - задача, которую он с присущей ему иронией ставит перед искусством и решает ее, соединяя философскую драму с фривольной комедией («Разговор в семействе Штайн об отсутствующем господине фон Гете», 1974; «Смерть Сенеки», 1980; «Живописец короля», 1991), эпические сюжеты с трагедией предательства («Фредегунда», 1984; «Геновева», 1993), комическую сказку с псевдоисторической хроникой («Магитср Кнауэрхазе», «Прилепа в птичьем гнезде»). В своих теоретических трудах «Хакс, как пишет Венгерова, - часто пристрастен и потому уязвим» [Венгерова, с. 457], однако в художественной практике он находит путь «показывать все и ничего не доказывать», «избегать апологетичности и некритичности», отражать «единство антагонистических противоречий в состоянии покоя» (Хакс, 2006, с. 35) через гротеск. Остранение, «великая и абсолютно открытая наивность в изображении противоречий» (Хакс, 2006, с. 41) достигаются столкновением несовместимых свойств образа, часто «вовсе не комедийным»«преувеличением, резким заострением» его характеристик [Зверев, c. 385], «сближением разнородных элементов, в результате которого и возникает алогичное единство» (курсив мой. - Д.К.); [Кобленкова, 2006, с. 29].

\section{Методы}

«Практически все теории гротеска, - пишет Тлостанова, - возникшие на Западе в XX в., были связаны с попытками дать ему некое философ- 
ское, онтологическое, а не только эстетическое толкование, что в сущности лишь подтверждает мысль о том, что гротеск - категория метапоэтики, не до конца бытийная, но и не целиком стилевая» [Тлостанова, с. 413]. Художественная практика П. Хакса подтверждает, что гротеск не может быть вписан в единый ряд с прочими тропами, «он есть не стилистический прием и не фигура речи, но - базовый принцип художественного осмысления (художественного моделирования) бытия» [Дормидонова, 2008а, с. 41; Дормидонова, 2008б], в связи с чем разговор о нем предполагает синтез методологических традиций формализма и мифопоэтики [Невяронович].

\section{Комическая деформация: «Величина» и «Величие»}

Если Бергсон писал о «механическом в живом» [Бергсон, с. 53], об обывательски-типовом, повторяющемся, то Хакс рисует мир вне тривиальности. Его установка - великие события, исторические катаклизмы, большие личности: «Цезарь совершает поступки Цезаря... Писатель способен создать великий характер без больших задач и целей в такой же малой мере, как природа. Герою нужна власть, он не пассивный, не страдающий, он субъект происходящего» (Хакс, 2006, с. 27). Вводя как основополагающее в своей исторической концепции понятие «Величина» (Größe), Хакс имеет в виду и масштаб события и смысловые коннотации, связывающие его с общей историей.

Нетривиальность сама по себе становится у Хакса мощным источником комизма. Гротесковый гигантизм призван выявить «величину» (в хаксовском двойственном - смысле слова) стоящих перед персонажами задач: «Работа императора - самая трудная работа, - пишет он в «Епископе Китая». Думать о ста миллионах человек ровно в миллион раз труднее, чем думать о ста» (Хакс, 2006, с. 248). «Учтивость гениев» целиком построена на столкновении мещанского сознания Хефцибы Николас и двух экстраординарных личностей - Эйнштейна и Менухина, способных ради приятного разговора пересечь континент и собрать целый оркестр для одного слушателя. Магистр Кнауэрхазе (в одноименной повести) требует от будущего короля, «чтобы его мудрость превосходила мою настолько, насколько его обязанности выше моих» (Хакс, 2006, c. 66), и грозит «верноподданейшим способом надавать ему по заднице» (Хакс, 2006, с. 66), если его величество не усвоит урока. Необходимые Телемаху учителя «заполонили все пути и дороги. Они заползали на склоны, где росли виноградники. Они вскарабкивались на прибрежные скалы. Они скапливались в оливковых рощах и воровали у крестьян инжир прямо с деревьев. Учителя налетели на страну, как саранча» (Хакс, 2006, с. 159-160).

Гиганты Хакса легко выстраиваются в типологический ряд. Совпадение величин личности, задач и исторической роли дает юмористический эффект [Иванова]. Несовпадение - гротескно-сатирический и даже гротескно-трагический: «С большими фигурами следует соблюдать осторожность. Они убивают, даже когда опрокидываются» (Хакс, 2006, c. 209).

Исключительность персонажей Хакса является прямым следствием его исторической концепции. Если великие предшественники Хакса, осмыслявшие историю в ХХ веке, исходят либо из окказиональной идеи бытийности, единичности (Музиль, Кафка), либо из идеи циклического (универсального) вечно повторяющегося движения (Брох, Г. Манн), то история Хакса - эволюционна, предопределенна и закономерна. Самое важное для человека, если следовать логике магистра Кнауэрхазе, это «1. Знание истории, 2. Объяснение истории, 3. Искусство рассматривать современные события как исторические, 4. Искусство направлять будущий ход истории в желательное русло» (Хакс, 2006, с. 59). Оптимизм Хакса во многом связан с его верой в социалистические идеи, однако прогресс (становление, улучшение и гармонизация) прямо легитимирует права искусства на выявление гротескного дуализма мира. «Развитие, если оно есть, - пишет он, - происходит в противоречиях и через противоречия» (Хакс, 1979, с. 29).

\section{Антитеза как путь к гротеску}

Безусловно, говоря о хаксовских гротесках, в перспективе следует разделить стратегии создания гротеска в пьесах, написанных до 1989 года и в 90-х, а также в пьесах и повестях. Однако, принимая во внимание, что сказки Хакса - зачастую «заготовки его будущих пьес или их эпизодов» [Венгерова, с. 456], сосредоточимся на общих смыслах и закономерностях.

Наиболее наглядно скрытый антагонизм мира выявляется у Хакса при столкновении «величины» со случайным, незначительным, мелким. Так, столкновение смерти и повседневности - «источник “жуткого" комизма» [Тлостанова, с. 429] в «Смерти Сенеки»: приговоренный и лицемерно принужденный к самоубийству философ не может достойно провести последние часы, поскольку втягивается домочадцами в склоки, разбирательства, скандал. Антитеза, формирующая ситуацию, двойная: великий Сенека в столкновении с пошлыми посетителями, готовящийся к смерти старец, вынужденный оправдываться из-за «нехорошей» болезни, которой он якобы заразился. Логика Лоты фон Штайн явственно показывает, насколько несовместимы представления о жизни Гете, веймарского света и ее собственные: «Он говорит, что создал "Тассо" и Ифигению, чтобы все знали, как он любит меня. Разумеется, все наоборот: он любит меня, чтобы сочинять этого Тассо и эту Ифигению. Я для него чернильный прибор» (Хакс, 2014a, c. 35). Их расставание - ее трагедия, предстающая наглядно в споре с самой собой, в комическом опрокидывании собственных оценок. Весь диалог гротесковое соединение двух стратегий: попытки унизить Гете до худшего из светских людей, неспособного любовника и бездарного собеседника и 
стремления представить роман с ним как единение душ и тел избранников, чьи помыслы и чувства никогда не будут доступны прочим.

Трагедии гениев находят окончательное выражение в непреодолимости деградации (цикл «Музы»). Итоговая ремарка: «Можно плакать» (Хакс, 2014б, с. 281) - «гротеск на грани смеха и кошмара» [Зверев, с. 385].

Не менее очевидна уязвимость исторических фигур в контексте мелких бытовых и физиологических подробностей, через которые «физическая природа вскрывает недостатки природы духовной» [Пропп, с. 34]. Из столкновения формы и содержания возникает отношение: «Карл Великий, Карл Толстый... Звучит похоже, но есть и разница, которую следует принять во внимание. Многие считают себя великими лишь потому, что разжирели» (Хакс, 2000, с. 213). Нравственная уязвимость обнаруживается через непоследовательность и «двойные стандарты»: «...видимость значительности, соединяется с ущербной духовной сущностью. Обнажение, развенчание этой видимости (посредством интеллектуального усилия, через физическую данность и т. д.) служит причиной для проявления смеха» [Дмитриев, Сычев, с. 219]. Рыдающая над охмелевшим щенком Галсвинта («Фредегунда» 1984) быстро ожесточается, когда понимает, что целью была проверка подаваемых вин на яды, а ее бокал остался не проверен. Зигфрид, женившийся повторно из политических соображений, долго отстаивает красоту своей жены, пока не признает, что потерпел поражение и как правитель, и как супруг.

\section{Формы гротеска в пьесах П. Хакса}

Создавая свой гротескный мир, Хакс активно использует весь арсенал накопленных литературой средств.

Столкновение масштабов: от физических размеров (великаны-боги и карлики «Телемах»), до значения событий (замысел и реализация «Смерть Сенеки», «Геновева» и др.) и возраста участников (малолетний Мервиг и королева Брунгильда «Фредегунда»).

Повторение, даже умножение, истории, которое «лишает духовный акт его творческого или вообще значительного характера» [Пропп, с. 47]: «Живописец короля», «Фредегунда», «Магистр Кнауэрхазе»и др.

Столкновение телесности и сексуальности на грани «полунеприличия» [Пропп; с. 36; Карасев, Козлова, Кривенькая] с вопросами политики (Барсина в повести «Магистр Кнауэрхазе»), искусства (О`Мерфи в пьесе «Живописец короля»), светскости (госпожа фон Штайн в «Разговоре в семействе Штайн об отсутствующем господине фон Гете»).

Соединение человеческого и животного миров, которое у Хакса организовано настолько тесным образом, что становятся плохо ощутимы границы: Филин влюблен в Принцессу, Прилепа не просто живет в птичьем гнезде, но и возглавляет войну обитателей сада против зловредных насекомых и т. д.

Гиперлокализация - внимание к материалу, его физическим свойствам, степени изношенности: кабинет Буше в «Живописце Короля», дверной звонок в «Учтивости гениев», картонный дом шершней в «Прилепе» и т. д.

Придание сугубо абстрактным понятиям физических свойств, например в истории «Прилепы»: «Дело в том, что войну можно спрятать так же, как шапку или носовой платок» (Хакс, 2006, с. 99).

Превращение или метаморфоза - одна из сказок Хакса так и называется «Мета Морфоз». Превращение - центральный мотив «Телемаха», причем очевидно выделяются «чудесные» и нечудесные превращения, связанные со старостью, человеческими отношениями и т. д. Так, старость Нестора наглядно видна, поскольку «его тело стало для него великовато и свисало складками» (Хакс, 2006, c. 184).

Многие из этих приемов прямо ориентированы на традицию фантастики, как известно, непосредственно связанной с гротеском. Утверждение Ю.В. Манна о том, что не гротеск служит фантастике, а фантастика гротеску, что ее роль - подчиненная [Манн, 1966] прямо воплощается в художественном мире Хакса.

Драматург активно абсурдирует ментальные категории и нравственные понятия: истина, добро, прогресс, патриотизм. Он описывает народ «смелый, патриотичный и вообще исполненный благих намерений. Беда в том, что они не могут этого запомнить» (Хакс, 2006, с. 93).

Сатирический эффект очевиден. Науки не дают знания, а лишь конструируют мир, исходя из соображений пользы и выгоды:

«Но числа вашей алгебры кровавы» («Фредегунда»).

«А не может ли середина Земли случайно оказаться в этом дворце? А именно на этом месте, которое случайно отмечено инкрустацией? Там, где случайно стою я» («Епископ Китая» (Хакс, 2014, c. 257)).

«Извлечь выгоду из теории глобуса, недурно!» («Колумб, или Путь к открытию мира» (Хакс, 1979, c. 19)).

Истина легко приспосабливаема к ситуации, интересам, нуждам тиранов:

- Может быть, в этом есть доля истины?

- Никакой, хоть это и правда» («Фраат» (Хакс, 2014, c. 266)).

«Всякая правдивость решительно вредит приобретению хлеба насущного» («Колумб, или Путь к открытию мира» (Хакс, 1979, с. 9)).

Однако следует подчеркнуть, что цель гротесков Хакса все же не обличение, а выявление скрытых смыслов. Его герои не скрывают истину, они искренне заблуждаются. Их собственные стремления часто лежат за пределами их понимания. На этом строится урок, даваемый испанским инфан- 
там в «Колумбе»: понять необходимо, не о чем думает или чего хочет человек, - необходимо понять, в чем он нуждается. Путь открытий, который проходят персонажи Хакса, не лишен потерь и разочарований, но в конечном итоге он приносит и позитивные плоды: «Что это за истина, если она не дает радости?» («Колумб, или Путь к открытию мира» (Хакс, 1979, с. 31)).

\section{Заключение}

Говоря о гротеске Хакса необходимо подчеркнуть, что кайзеровское двойничество (как основа гротеска в форме расщепленной идентичности, «демонического другого» (цит. по: [Тлостанова, с. 411]) находит свое отражение в системе образов почти каждой пьесы и повести Хакса. Двойники Шуйский и Лжедмитрий, двойники Старый и Новый короли Сушасуши в «Магистре Кнауэрхазе» и т. д. Не просто противоречие двух «Я», но их отчуждение и враждебность - условия гротеска, выдвигаемые в монографии В. Кайзера (цит. по: [Тлостанова, с. 411]). У Хакса антагонистические противоречия возникают между персонажами с наиболее сходными целями. Дикарь и Магистр в повести «Магистр Кнауэрхазе» не просто похожи: «Более всего он походил на меня тогда, когда вовсе не был похож!» (Хакс, 2006, с. 75). «Фредегунда» строится на том, что двойников как минимум четверо - молодые королевы, рвущиеся к власти и думающие, что мир движут их интриги. В итоге оказывается, что параллельно разворачивалась интрига, которую вели их мужья-короли. Вся трагедия, как выяснилось, разыгрывалась в удвоенном (мужская и женская половины) пространстве. Двойников оказывается не четверо, а девятеро. Однако среди них нет ни одного, чей замысел воплотился бы в полной мере. Поскольку история для Хакса объективный процесс, она движется не личными устремлениями, а тем «напряжением», которое возникает между осуществляющими ее движение «Величинами». В итоге мир почти неизбежно приходит к точке равновесия. Их противоположные стремления уравновешивают друг друга. Результат: содержащая в себе внутреннюю энергию распада, опасная, но все же гармония.

\section{Источники фактического материала}

Манн Г. Зрелые годы короля Генриха IV/ пер. Н. Касаткиной. М.: Худ. лит., 1978. 752 с.

Хакс П. Герои и поэты. М.: Райхль, Иностр. лит., 2014a. $440 \mathrm{c}$.

Хакс П. Мужи и музы. М.: Райхль, Иностр. лит., 20146. $296 \mathrm{c}$.

Хакс П. Мета Морфоз и другие сказки. М.: РГГУ, 2000. $282 \mathrm{c}$.

Хакс П. Повести. М.: evidentis, 2006. 215 с.

Хакс П. Пьесы. М.: Искусство, 1979. 503 с.

\section{Библиографический список}

Бергсон А. Смех. М.: Искусство, 1992. 128 с.

Венгерова Э. Поэтический театр Петера Хакса // Хакс П. Пьесы. М.: Искусство, 1979. С. 449-484.

Дежуров А.С. Гротеск в немецкой литературе XVIII века: автореф. дис. ... канд. филол. наук. М., 1996. $21 \mathrm{c}$.

Дмитриев А.В., Сычев А. Смех. Социофилософский анализ. М.: Альфа-М, 2005. 592 с.

Дормидонова Т.Ю. Гротеск как литературоведческая проблема // Известия Российского государственного педагогического университета им. А.И. Герцена. 2008а. № 51. C. 40-44. URL: https://elibrary.ru/ item.asp?id=12512654.

Дормидонова Т.Ю. Гротеск как тип художественной образности: автореф. дис. ... канд. филол. наук. Тверь, 2008 б. 22 c.

Зверев А.М. Смеховой мир // Художественные ориентиры зарубежной литературы ХХ века. М.: ИМЛИ PAH, 2002. C. 378-408.

Иванова И.Ю. Современный гротеск и поэтика абсурда в условиях гиперцепции // Ученые записки Российского государственного социального университета. 2012. № 10 (110). C. 156-158. URL: https:// elibrary.ru/item.asp?id=20685938.

Карасев Л.В. Философия смеха. М.: РГГУ, 1996. 232 с.

Кобленкова Д.В. Проблемы становления теории гротеска // Новый филологический вестник. № 2 (3). 2006. C. 26-36. URL: http://slovorggu.ru/nfv2006_2_3_pdf/ 03Koblenkova.pdf.

Козлова Д.В. Основные подходы к определению понятия «Гротеск» // Вестник Нижегородского университета им. Н.И. Лобачевского. Серия: Филология. 2000. № 1. C. 119-124. URL: http:// www.un n. ru / pages / is sues / vestnik/99990196_West_filol_2000_1(2)/16.pdf.

Кривенькая Е.С. Преломление элементов смеховой культуры в карикатуре // Искусство и культура. 2014. № 3 (15). C. 85-94. URL: http://lib.vsu.by/xmlui/handle/ $123456789 / 4776$.

Манн Ю. О гротеске в литературе. М.: Сов. писатель, 1966. 184 с.

Невяронович Н.Ю. Гротескная транскрипция эсхатологического мифа в романе А. Слаповского «Первое второе пришествие» // Литература в контексте современности. Челябинск: ЧГПУ, 2007. С. 219-223

Пропп В.Я. Проблемы комизма и смеха. Ритуальный смех в фольклоре. М.: Лабиринт, 2006. 256 с.

Тлостанова М.В. Гротеск в литературах Запада // Художественные ориентиры зарубежной литературы ХХ века. М.: ИМЛИ РАН, 2002. С. 408-440.

\section{References}

Bergson A. Smekh [Laughter]. M.: Iskusstvo, 1992, 128 p. [in Russian].

Vengerova E. Poeticheskiy teatr Petera Haksa [Poetry theater of Peter Hacks]. In: P. Hacks. P'yesy [Plays]. M.: Iskusstvo, 1979, pp. 449-484 [in Russian].

Dezhurov A.S. Grotesk v nemetskoi literature XVIII veka: avtoref. dis... kand. filol. nauk [Grotesque in German 
literature of the XVIII century: author's abstract of Candidate's of Philological Sciences thesis]. M., 1996, 21 p. [in Russian].

Dmitriev A.V., Sychev A. Smekh. Sotsiofilosofskiy analiz [Laughter. Socio-philosophical analysis]. M.: Alfa-M, 2005, 592 p. [in Russian].

Dormidonova T.Yu. Grotesk kak literaturovedcheskaya problema [Grotesque as a literary problem]. Izvestiya Rossiyskogo gosudarstvennogo pedagogicheskogo universiteta im. A.I. Gertsena [Izvestia: Herzen University Journal of Humanities \& Science], 2008 a, no. 51, pp. 40-44 [in Russian]. Available at: https://elibrary.ru/item.asp?id= 12512654.

Dormidonova T.Yu. Grotesk kak tip khudozhestvennoi obraznosti: avtoref. dis. ... kand. filol. nauk [Grotesque as a type of artistic imagery: author's abstract of Candidate's of Philological sciences thesis]. Tver, 2008 b, 22 p. [in Russian].

Zverev A.M. Smekhovoy mir [The laughing world]. In: Khudozhestvennye orientiry zarubezhnoi literatury XX veka [Artistic landmarks of foreign literature of the XX century]. M.: IMLI RAN, 2002, pp. 378-408 [in Russian].

Ivanova I.Yu. Sovremenniy grotesk i poetika absurda $\mathrm{v}$ usloviyakh gipertseptsii [Modern grotesque and poetics of the absurd in conditions of hypertension]. Uchenyye zapiski Rossiyskogo gosudarstvennogo sotsial'nogo universiteta [Scientific notes of the Russian State Social University], 2012, no. 10 (110), pp. 156-15. Available at: https://elibrary.ru/item.asp?id=20685938 8 [in Russian].

Karasev L.V. Filosofiya smekha [Philosophy of laughter]. M.: RGGU, 1996, 232 p. [in Russian].
Koblenkova D.V. Problemy stanovleniia teorii groteska [Problems of the formation of the grotesque theory]. Novyi filologicheskiy vestnik [New Philological Bulletin], 2006, no. 2 (3), pp. 26-36. Available at: http://slovorggu.ru/ nfv2006_2_3_pdf/03Koblenkova.pdf [in Russian].

Kozlova D.V. Osnovnyye podkhody $k$ opredeleniyu ponyatiya «Grotesk» [The main approaches to the definition of the concept «Grotesque»]. Vestnik Nizhegorodskogo universiteta im. N.I. Lobachevskogo. Seriia: Filologiia [Vesnik of Lobachevsky University of Nizhni Novgorod. Series: Philology], 2000, no. 1, pp. 119-124 [in Russian]. Available at: http://www.unn.ru/pages/issues/vestnik/99990196 West filol_2000_1(2)/16.pdf.

$\overline{\mathrm{M}}$ ann $\overline{\mathrm{Y}} \mathrm{u} . \overline{\mathrm{O}}$ groteske $\mathrm{v}$ literature [On the grotesque in literature]. M.: Sov. pisatel', 1966, 184 p. [in Russian].

Nevyaronovich N.YU. Grotesknaya transkriptsiya eskhatologicheskogo mifa $\mathrm{v}$ romane A. Slapovskogo «Pervoye vtoroye prishestviye»[Grotesque transcription of the eschatological myth in the novel by A. Slapovsky "The First Second Coming»]. Literatura v kontekste sovremennosti [Literature in the Context of Modernity]. Chelyabinsk: ChGPU, 2007, pp. 219-223 [in Russian].

Propp V.Ya. Problemy komizma i smekha. Ritual'nyi smekh $\mathrm{v}$ fol'klore [The problems of comic and laughter. Ritual laughter in folklore]. M.: Labirint, 2006, 256 p. [in Russian].

Tlostanova M.V. Grotesk v literaturakh Zapada [Grotesque in the Western literature]. In: Khudozhestvennye orientiry zarubezhnoi literatury XX veka [Artistic landmarks of foreign literature of the XX century]. M.: IMLI RAN, 2002, pp. 408-440 [in Russian]. 